Article

\title{
An Assessment of the Spatial and Temporal Distribution of Soil Salinity in Combination with Field and Satellite Data: A Case Study in Sujawal District
}

\author{
Kashif Ali Solangi ${ }^{1}$, Altaf Ali Siyal ${ }^{2}$, Yanyou Wu ${ }^{1}$,, Bilawal Abbasi $^{3}{ }^{(D}$, Farheen Solangi $^{3}$, \\ Imran Ali Lakhiar ${ }^{1}$ (D) and Guiyao Zhou ${ }^{4}$ \\ 1 Key Laboratory of Modern Agricultural Equipment and Technology, Ministry of Education, \\ Institute of Agricultural Engineering, Jiangsu University, Zhenjiang 212013, Jiangsu, China; \\ 5103180312@stmail.ujs.edu.cn (K.A.S.); 5103160321@stmail.ujs.edu.cn (I.A.L.) \\ 2 U.S.-Pakistan Center for Advanced Studies in Water Mehran University of Engineering \& Technology, \\ Jamshoro 76062, Sindh, Pakistan; aasiyal.uspcasw@faculty.muet.edu.pk \\ 3 Institute of Agricultural Resources and Regional Planning, Chinese Academy of Agricultural Sciences, \\ Beijing 100081, China; 2018Y90100003@caas.cn (B.A.); feryssolangi@yahoo.com (F.S.) \\ 4 Zhejiang Tiantong Forest Ecosystem National Observation and Research Station, Center for Global Change \\ and Ecological Forecasting, East China Normal University, School of Ecological and Environmental Sciences, \\ East China Normal University, Shanghai 200241, China; jdzhouguiyao@163.com \\ * Correspondence: wuyanyou@mail.gyig.ac.cn; Tel.: +86-0851-8439-1746
}

Received: 1 November 2019; Accepted: 6 December 2019; Published: 10 December 2019

\begin{abstract}
Soil salinization is a serious environmental issue that significantly influences crop yield and soil fertility, especially in coastal areas. Numerous studies have been conducted on the salinity status in Pakistan. Information about the geospatial and temporal distribution of salinity in the Sujawal district is still lacking. The present study examines the soil salinity status and the impact of seawater intrusion in the entire district from 1990 to 2017 using field and remote sensing (RS) data. In addition, 210 soil samples at different depths $(0-20,20-40$, and 40-60 cm) were collected from randomly selected locations for lab measurements of physiochemical properties. The results showed that the soil texture classes were mainly fine to medium particles. The samples collected at the $0-20 \mathrm{~cm}$ depth were mostly dominated by three textural classes of soil: clay at $19.5 \%$, clay loam at $25.6 \%$, and loam at $32.9 \%$. The electrical conductivity (EC) of $65.7 \%$ soil samples collected from the top layer exceeded the normal range. The quantitative results indicated that the exchangeable sodium percentage (ESP) ranged between 1.38 and 64.58 , and $72.2 \%$ of the top layer soil samples had ESP $>15$, while $81.5 \%$ of soil samples were in the normal range of soil $\mathrm{pH}$. Furthermore, the results indicated that the vegetation decreased by $8.6 \%$ from 1990 to 2017, while barren land and water bodies increased significantly, by approximately $4.4 \%$ and $4.2 \%$, respectively. The extreme and high salinity classes were characterized by high contents of soluble salt on the surface in the Jati and Shah Bandar subdistricts. In addition, the soil EC values at the $0-20 \mathrm{~cm}$ depth were significantly correlated with the salinity index (S1). Therefore, it was concluded that more than $50 \%$ of the top layer of soil was affected by salinity due to seawater intrusion, low rainfall, climate change, and erratic river flow. It is suggested that remote sensing (RS) data are more suitable for the detection of the soil salinity status of a region and impose a lower cost compared to other conventional approaches. However, this study could provide significant knowledge to land managers, policymakers, and government officials to allow them to take action to implement salinity control measures in the study area.
\end{abstract}

Keywords: soil salinity; field surveys; remote sensing; salinity indices; Sujawal district 


\section{Introduction}

Soil salinity is a serious environmental problem throughout the world, especially in arid and semi-arid agricultural land [1,2]. It has been reported that most of the irrigated agricultural land of China, India, Pakistan, and the United States of America suffers from salinity problems [3]. Currently, nearly $20 \%$ of irrigated farmland around the world is experiencing severe salinity problems, which not only threatens crop growth but also degrades fertile agricultural land. Therefore, understanding the distribution of soil salinity is important for us to enhance future agriculture management.

Sindh province is the second-largest agricultural contributor of Pakistan, where more than 2.5 million hectares of arable land are under salinity cover [4]. Generally, salt flows from upstream regions to lower regions, which might be the principal factor contributing to the increased salinity problem in Sindh province. SIDA [5] reported that, due to increasing salinization, Sindh requires more attention compared to other provinces in Pakistan. Generally, soil salinity has been measured by traditional soil analysis methods, which are considered costly and time-consuming [6]. Previous studies reported that remote sensing (RS) data provide quick results and represent a low-cost method as compared to traditional methods $[7,8]$. Remote sensing (RS) data have great potential and can be widely used to detect soil salinity spatially and temporally [9]. Furthermore, RS data could be used in different ways, such as in comparison with field data [10]. The basic spatial information-based methods are spatial interpolation approaches, including inverse distance weighting (IDW), kriging, cokriging, spline function, and geostatistical interpolation methods [11,12]. These methods are effective for the spatial distribution of soil salinity with limited spatial information [13,14]. The inverse distance weighting (IDW) method depends on determining the center of two known points; according to this method, the near points have more weight than distant points and vice versa [15].

There are a number of satellites and sensors that are widely used for monitoring soil salinity [16]. However, these sensors are mainly used to measure the salinity from the soil surface; moreover, they measure salinization problems, with the entire soil profile used to explore salinization problems in the area.

Quantification and mapping of soil salinity dynamics are essential for better planning and soil reclamation processes, along with the prevention of ecological degradation [17]. Sujawal district is more vulnerable to climate change impacts, i.e., droughts and floods caused by the erratic flow of the Indus River. It is continuously threatened by seawater intrusion. Fertile agricultural land changed into saline and became less productive, which led to a threat to agricultural sustainability and the socioeconomic conditions in the district [18,19]. However, the spatial and temporal distribution of soil salinity remains poorly understood, although some individual studies have been conducted before. In order to solve this problem, the present research used ground data at different soil depths and compared them to RS data to investigate the status of soil salinity in Sujawal district.

In view of this scenario, the main objectives of the present study were to: (i) explore the soil salinity status and impact of seawater intrusion in the entire district from 1990 to 2017, and (ii) investigate the relationships between field data and soil salinity indices.

\section{Materials and Methods}

\subsection{Study Area}

Sujawal is a southern district of Sindh province, located between $36^{\circ} 59^{\prime} 23^{\prime \prime} \mathrm{N}$ and $68^{\circ} 4^{\prime} 19^{\prime \prime} \mathrm{E}$ (Figure 1). The total area covered by the district is about $8614.2 \mathrm{~km}^{2}(861,420.78$ hectares), which is divided into four subdistricts, Jati, Bathoro, Shah Bandar, and Sujawal, and further divided into 30 union councils. The maximum temperature is $45^{\circ} \mathrm{C}$ during the summer season, especially the month of June, and it falls to $10^{\circ} \mathrm{C}$ in the month of January. The maximum rainfall was recorded in the monsoon season months of July-September and the minimum rainfall was recorded in November-March; the average annual rainfall was about $220 \mathrm{~mm}$ [20]. The climatic zones are dry and tropical [18]. The main crops in Sujawal district are wheat, rice, sugarcane, bananas, and tomatoes. The agricultural cropping system 
mainly depends on the canal irrigation system, supplemented with groundwater. Groundwater is mostly used for drinking [21].

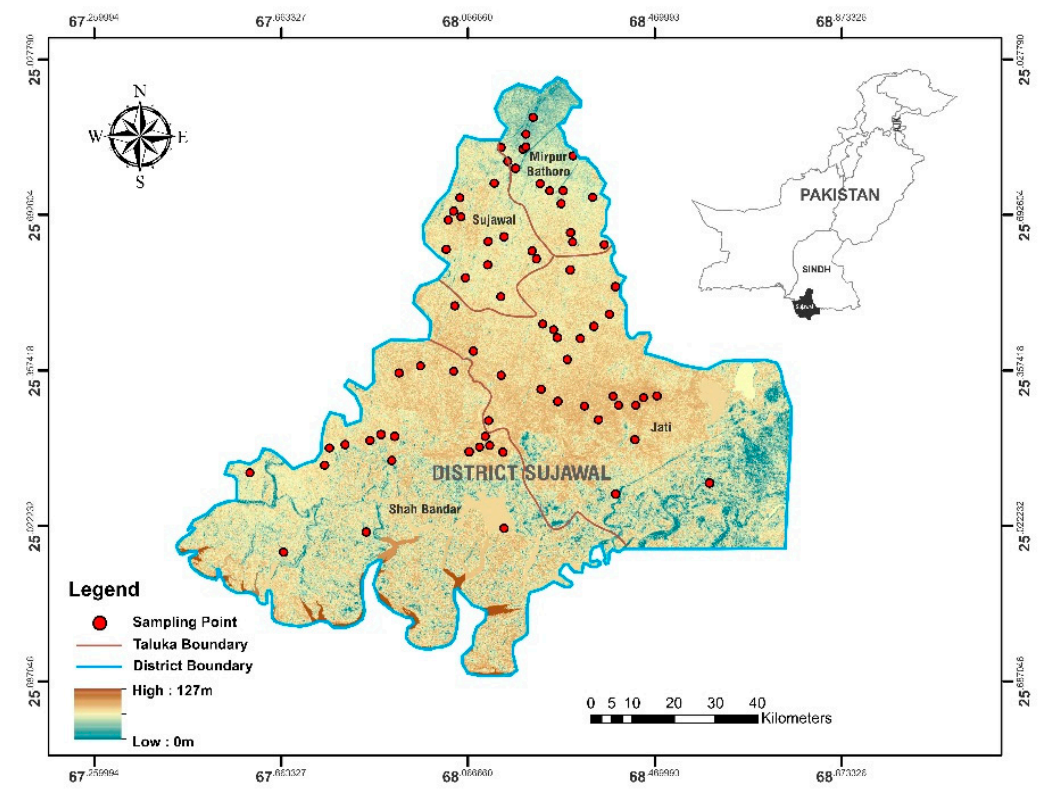

Figure 1. Location map of the study area and sampling points.

\subsection{Geo-Reference Soil Sampling}

Soil samples were randomly collected from different locations of the study area in September to December 2016. The coordinates were recorded using hand-held Garmin GPS-62s [21]. Before the field survey we added sampling points in the hand-held GPS-62s with coordinates for tracking the route and finding easy sampling points. Samples were collected at several depths (0-20, 20-40, and 40-60 cm), with the help of a soil auger, packed into plastic bags, labeled with the sampling depth as well as the geographical location, and carried to the laboratory for analysis. Samples were air-dried at room temperature and passed through 2-mm and <2-mm sieves; for the electrical conductivity (EC) analysis we used <2-mm. Subsample portions were stored for $\mathrm{pH}$, exchangeable sodium percentage (ESP), and dry density analysis. In total, 210 samples were collected from Sujawal district. One sample was collected from each depth at the locations shown in Figure 1.

\subsection{Soil Properties Analysis Based on Spatial Mapping}

Textural classes were determined by the Bouyoucos method according to the USDA textural triangle [22]. The Electrical conductivity (EC) soil saturation extract was determined at $25{ }^{\circ} \mathrm{C}$ using an EC meter (Hanna Model-8733, Germany). Soil $\mathrm{pH}$ was determined in a soil and water mixture (1:2 ratio) using a pH meter (Jenway, Model-3510, Gransmore Green, Felsted, Dunmow, Essex, CM6 3LB, $\mathrm{UK})$ and the calcium $\left(\mathrm{Ca}^{+}\right)$, and magnesium $\left(\mathrm{Mg}^{+}\right)$contents of the soil determination EDTA titration method [19]. The sodium concentration was extracted with $1 \mathrm{M}$ ammonium acetate $\left(\mathrm{NH}_{4} \mathrm{OAc}\right)$ solution and measured by a flame photometer as in the method previously described in [23]. Results were calculated based on the sodium absorption ratio (SAR) and ESP (equations) empirical formulas [24]. The quantitative results of physicochemical properties were found using ArcGIS 10.3 software, ESRI, New York street Redlands, Califorina, USA. The IDW tool used for spatial mapping of physicochemical properties and areas of interest was extracted using the 'extraction by mask' tool [25].

\subsection{Acquisition of Satellite Data and Classification of Imagery}

The current study used images acquired by the clear sky Landsat 5 and 8 satellites of WRS-2 path 151 \& 152, row 43, processing Level 1T, from the United States Geological Survey (USGS, 2017) 
portal (http://glovis.usgs.gov) for the months of February 1990 and February 2017. Later, the area of interest (AOI) was extracted from the original imagery using the shape file of Sujawal district as a mask in ArcGIS 10.3 software. After that, we created signature files for salinity-affected areas and acquired classified maps of the district; the maximum likelihood classification algorithm was used with supervised classification. The supervised classification is considered to give more accurate results than unsupervised classification [26]. The research area was calculated from the maps and classified into barren land, water bodies, and vegetation by converting the raster image into vector polygons. Thereafter, accuracy assessment was an important step to verify the image classification. In total, 90 points were taken as test samples to compare the accuracy with the reference data. Furthermore, a total of four scenes were acquired for the study area from GloVis for imagery classification and the detection of soil salinity (Table 1).

Table 1. Satellite imagery used for the present study.

\begin{tabular}{cccccccc}
\hline S\#No & Landsat Scene ID & Date of Acquisition & Path & Row & DOY & $\boldsymbol{d}$ & $\boldsymbol{\theta}_{\boldsymbol{s}}$ \\
\hline 1 & LT515204319900321SPOO & $01 / 02 / 1990$ & 151 & 43 & 32 & 0.98536 & 38.963608 \\
2 & LT515104319900411SPOO & $10 / 02 / 1990$ & 152 & 43 & 41 & 0.98680 & 37.253531 \\
3 & LC81510432017051LGN00 & $28 / 02 / 2017$ & 151 & 43 & 59 & 0.98817 & 46.110403 \\
4 & LC81520432017042LGN00 & $18 / 02 / 2017$ & 152 & 43 & 49 & 0.98835 & 43.506486 \\
\hline
\end{tabular}

Note: * DOY (day of the year), d (earth-sun distance in astronomical units), $\theta_{s}$ (solar zenith angle degrees).

Soil salinity indices are considered a powerful tool for identifying soil surface salinity and analyzing soil properties; the relative maximum difference value bands were selected for developing the salinity indices, which are related to spectral patterns. Researchers have developed various indices $[13,26,27]$. In the present study, we used three standard salinity indices for the detection of soil salinity, summarized in Table 2. The methodology adopted in the present study is depicted in Figure 2.

Table 2. Salinity indices, equations, and references.

\begin{tabular}{ccc}
\hline Salinity Indices & Equations & References \\
\hline Normal differential salinity index & $\mathrm{NDSI}=(\mathrm{R}-\mathrm{NIR}) /(\mathrm{R}+\mathrm{NIR})$ & Khan et al. (2005) \\
Salinity Index 1 & $\mathrm{SI}=(\mathrm{B}-\mathrm{R}) /(\mathrm{B}+\mathrm{R})$ & Abbas and Khan $(2007)$ \\
Salinity index 2 & $\mathrm{S} 2=(\mathrm{G} \times \mathrm{R}) / \mathrm{B}$ & Abbas and Khan $(2007)$ \\
\hline
\end{tabular}

Note: Normal differential salinity index (NDSI), salinity index 1 (S1), and salinity index 2 (S2).

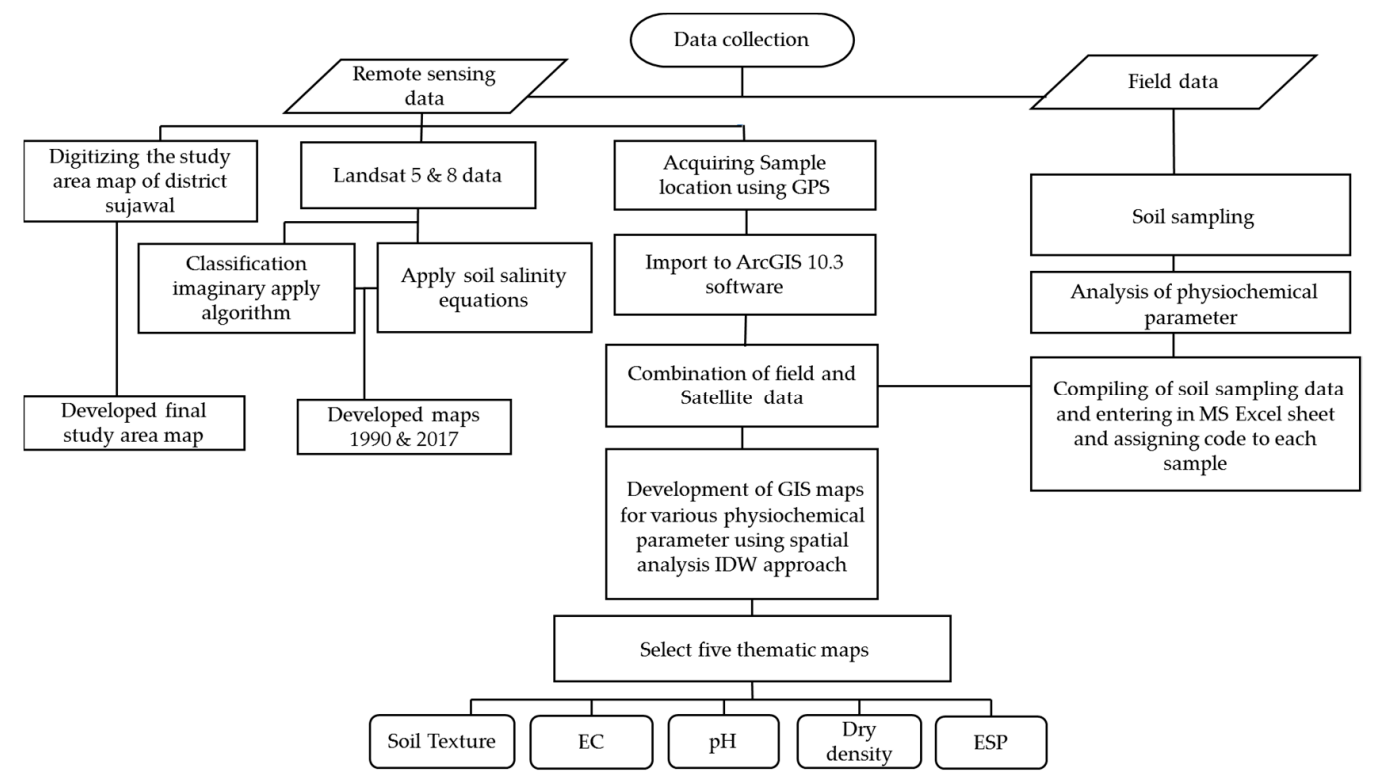

Figure 2. Flowchart of methodology. 


\section{Results and Discussion}

\subsection{Soil Textural Classes}

The spatial variation of soil texture at the 0-20 cm layer in Sujawal district is dominated by six different classes (Figure 3). Soil texture is an important factor influencing soil salinity [24]. Moreover, the fine textural class leads to more salt accumulation in the topsoil [28]. Based on the soil analysis, the top layer of most of the three classes was dominated by different percentages such as clay (19.5\%), clay loam (25.6\%), and loam (32.9\%). At to the subdistrict level, these soil textural classes mostly dominated in the Jati and Shah Bandar areas. The subsurface soil layers (20-40 and 40-60 cm) contain similar soil textural classes. According to a previous study, the Indus River carries 49.6\% clay, 45.4\% silt, and 5\% sand, so a dominance of alluvial soil was found in Sujawal district [29]. Hence, Sujawal district is located at the lower end of the Indus River and has a flat topography, which might explain why it is dominated by fine-textured soil.

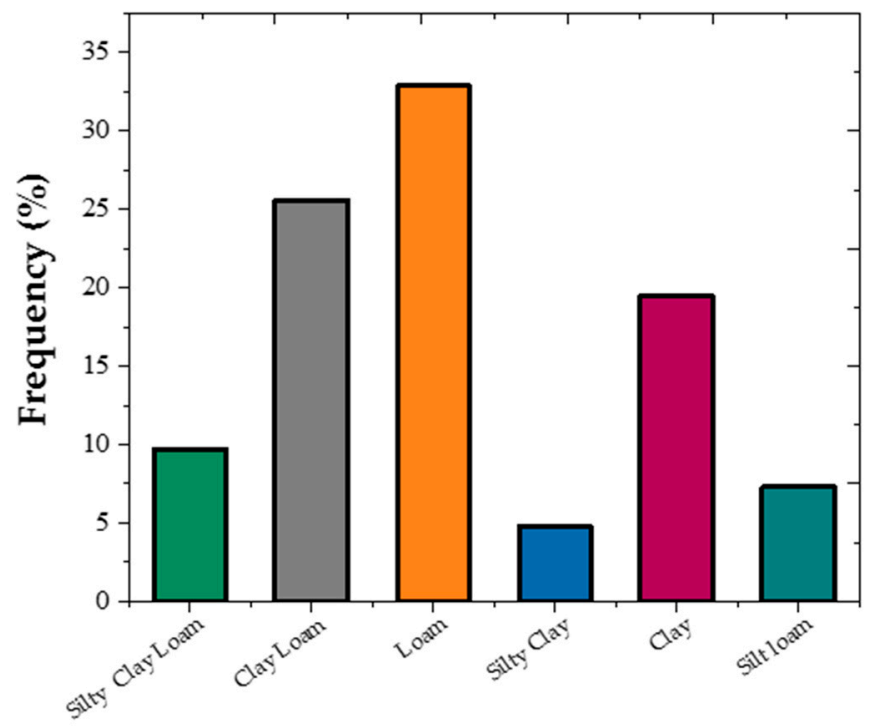

Figure 3. Spatial variation in soil textural classes of the top layer $(0-20 \mathrm{~cm})$ soil depth.

\subsection{EC and $p H$ Analysis}

The quantitative results of four major soil salinity parameters, namely EC, $\mathrm{pH}, \mathrm{ESP}$, and dry density at different soil depths (0-20, 20-40, and 40-60 cm), are presented in Table 3 with descriptive statistics such as the minimum, maximum, mean, standard deviation (STD), and confidence interval (CI). In this regard, $65.7 \%$ of soil samples had an EC higher than $4 \mathrm{dS} / \mathrm{m}$, indicating that large areas of the soil range between moderately saline and extremely saline. In contrast, $57.5 \%$ of subsurface $(20-40 \mathrm{~cm})$ soil samples were found to be affected by salt, while in the case of soil samples at the 40-60 cm depth, 54.5\% were declared to be saline. As reported by [28], the soil is considered saline if the EC value exceeds $4 \mathrm{dS} / \mathrm{m}$. The spatial distribution of EC, as determined by the advanced geostatistical method IDW at a 0-20 cm depth, is shown in Figure 4a. Solangi et al. [30] reported that a soil EC value of $0.7 \mathrm{dS} / \mathrm{m}$ or less is not stressful to most plants. Similarity was seen to previous research: salinity could be attributed to the use of saline water for irrigation, and, subsequently, it has effects on productive lands [31] (Faouzi and Larabi, 2001). A higher magnitude of soil salinity was found near the coastal region of the district; this might be due to seawater intrusion. The present results are in agreement with the previous finding that $89.4 \%$ of groundwater had a higher EC in Sujawal district due to sea intrusion and the decreased flow of the Indus River [18]. 
Table 3. Physicochemical analysis of soil samples at the various depths $(0-20,20-40$, and $40-60 \mathrm{~cm})$.

\begin{tabular}{cccccc}
\hline Parameters & Min & Max & Average & STD & CI \\
\hline \multicolumn{7}{c}{ Depth 0-20 cm } \\
\hline EC & 0.50 & 46.6 & 14.2 & 14.8 & 1.20 \\
pH & 9.20 & 6.80 & 7.93 & 0.54 & 0.90 \\
ESP & 1.38 & 64.58 & 26.9 & 16.3 & 1.29 \\
Dry density & 1.19 & 1.35 & 1.27 & 0.04 & 0.02 \\
\hline \multicolumn{7}{c}{ Depth 20-40 cm } \\
\hline EC & 0.60 & 48.0 & 11.5 & 12.8 & 1.30 \\
pH & 7.10 & 9.10 & 8.02 & 0.48 & 0.80 \\
ESP & 5.24 & 65.9 & 27.5 & 16.22 & 1.29 \\
Dry density & 1.19 & 1.35 & 1.27 & 0.04 & 0.02 \\
\hline \multicolumn{7}{c}{ Depths 40-60 cm } \\
\hline EC & 0.70 & 41.8 & 9.80 & 10.87 & 1.42 \\
pH & 7.20 & 9.10 & 8.00 & 0.47 & 0.80 \\
ESP & 3.66 & 65.1 & 27.5 & 15.64 & 1.32 \\
Dry density & 1.17 & 1.34 & 1.26 & 0.04 & 0.01 \\
\hline
\end{tabular}

Note: Electrical conductivity (EC), soil $\mathrm{pH}(\mathrm{pH})$, exchangeable sodium percentage (ESP), and dry density.
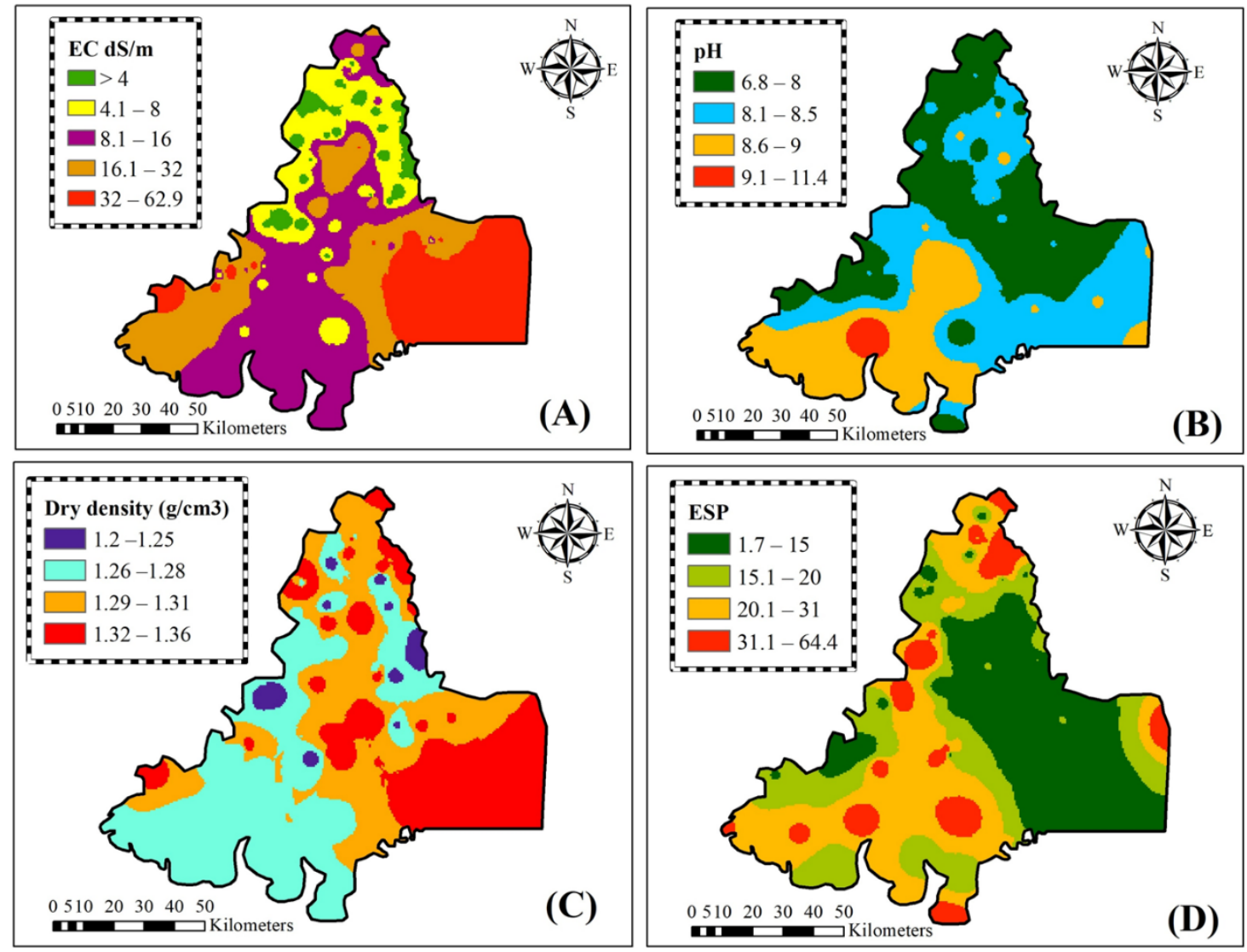

Figure 4. Spatial distribution of thematic maps: (A) electrical conductivity, dS/m; (B) soil pH; (C) Dry density $\mathrm{g} / \mathrm{cm}^{3}$; (D) exchangeable sodium percentage (ESP) of Sujawal district at a 0-20 cm soil depth.

The magnitude of soil salinity at the top layer $(0-20 \mathrm{~cm})$ is higher $(14.2 \mathrm{dS} / \mathrm{m})$ compared to the other subsurface soil salinity analysis; these results are consistent with previous results from [32]. Due to an improper recharge and discharge rate, the groundwater level increased, which causes subsoil 
salts to move up and accumulate in topsoil. As has been reported, topsoil $(0-10 \mathrm{~cm})$ had a higher salinity compared to the subsoil [33].

In terms of $\mathrm{pH}$, the top layer $(0-20 \mathrm{~cm}$ depth) varied from 6.8 to 9.2 , with an average value of $7.93 \pm 0.9$. Generally, soil at $\mathrm{pH}>8.5$ is considered to be salt-affected; in this study, $81.5 \%$ of top layer soil samples had a $\mathrm{pH}<8.5$. The spatial distribution of soil $\mathrm{pH}$ at $0-20 \mathrm{~cm}$ soil depth is portrayed in Figure $4 \mathrm{~b}$. The results of ESP shown in Table 3 for the $0-20 \mathrm{~cm}$ depth varied between 1.38 to 64.58 , with an average of $26.89 \pm 1.29$. About $72.2 \%$ of soil samples' ESP was $>15$, which is considered salt-affected. Values of ESP $<15$ and soil $\mathrm{pH}<8.5$ indicate saline soils [34]. The spatial distribution of ESP at $0-20 \mathrm{~cm}$ depth is shown in Figure $4 \mathrm{~d}$, and it is clear from the figure that higher ESP was found near the coastal region of the district. Soil salinity is also affected by physical characteristics of the soil such as pore size distribution and structure.

\subsection{Classification of Imagery Acquired from February 1990 and February 2017}

To assess the temporal distribution of soil salinity, clear-sky satellite data (Landsat $5 \mathrm{TM}$ and Landsat 8 OLI) were acquired from a data access portal (USGS 2017) over the entire district of Sujawal for February 1990 and February 2017. The scenes that were acquired for the study area are presented in Figure 5; large areas are occupied by tidal flood plains, along with the coastal regions of the district. The unclassified satellite imagery was classified using a likelihood classification algorithm by creating three regions of interest based on the ground truth data and the true color of the satellite data. The results of the classified imagery are given in Table 4. During February 1990, about 36.6\% of the total geographical area was occupied by vegetation, $10.7 \%$ was associated with water bodies, and approximately $52.7 \%$ was barren land. A dominance of barren land was found mostly between irrigated agriculture land in the northern part of the district and tidal floodplains in the southern subdistrict areas of Jati and Shah Bandar (Figure 5). The results of the imagery classification of 2017 are given in Table 4 . The vegetation area was $28 \%$, barren land was $57.1 \%$, and water bodies were $14.9 \%$. The quantitative results indicated that the vegetative area decreased significantly, by $8.6 \%$. Meanwhile, barren land and water bodies increased were by $4.4 \%$ and $4.2 \%$, respectively. The results of the accuracy assessment demonstrate that there was a high rate of accuracy for the classified image in 2017. The user accuracy for vegetation, barren land, and water bodies was $90.3 \%, 87.0 \%$, and $93.1 \%$, while producer accuracy was $91.1 \%, 92.0 \%$, and $88.4 \%$ for vegetation, barren land and water bodies, respectively. Lea and Curtis [35] reported that an accuracy assessment requires an overall classification accuracy of over $90 \%$, which was achieved in this study.
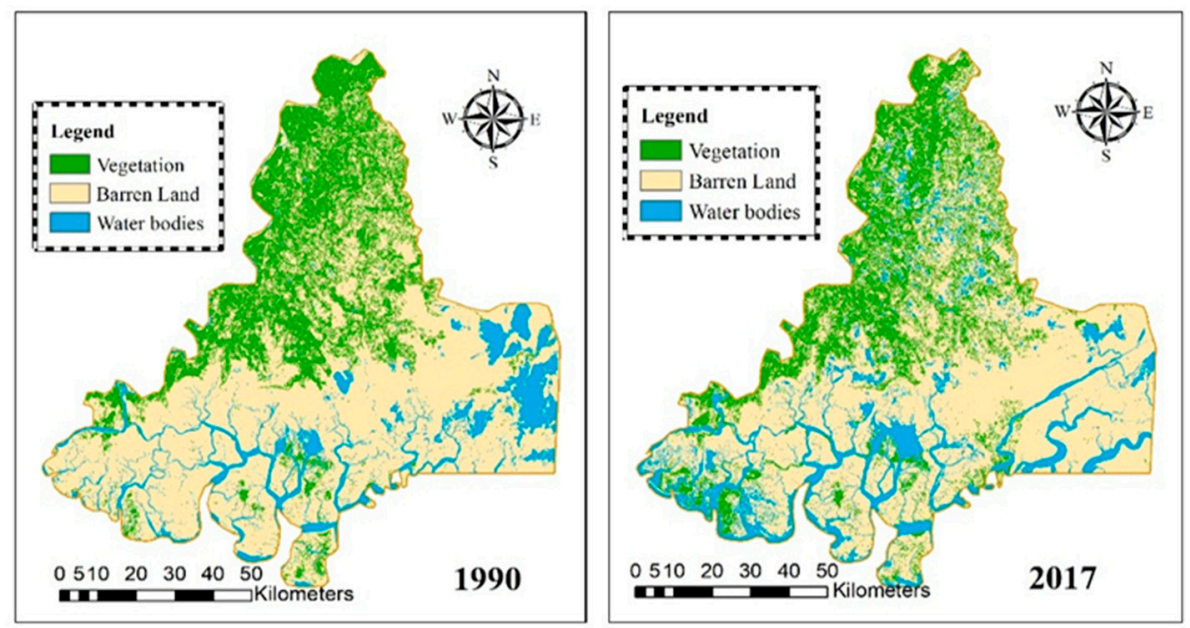

Figure 5. The classified satellite images from February 1990 and February 2017 for Sujawal district. 
Table 4. Temporal variations in Landsat Satellite imagery between February 1990 and February 2017.

\begin{tabular}{cccccc}
\hline $\begin{array}{c}\text { Land } \\
\text { Utilization }\end{array}$ & $\begin{array}{c}\text { Area (ha) } \\
\mathbf{( 1 9 9 0 )}\end{array}$ & $\begin{array}{c}\text { Area (ha) } \\
\mathbf{( 2 0 1 7 )}\end{array}$ & $\begin{array}{c}\text { Total Geographical } \\
\text { Area (\%) (1990) }\end{array}$ & $\begin{array}{c}\text { Total Geographical } \\
\text { Area (\%) (2017) }\end{array}$ & $\begin{array}{c}\text { Total Difference in } \\
\text { Geographical Area (\%) } \\
\text { between 1990 and 2017 }\end{array}$ \\
\hline $\begin{array}{c}\text { Vegetation } \\
\text { Barren land }\end{array}$ & 315,373 & 241,379 & 36.6 & 28 & $-8.6 \%$ \\
$\begin{array}{c}\text { Water bodies } \\
\text { Total }\end{array}$ & $92,163.2$ & $492,222.3$ & 52.7 & 57.1 & +4.4 \\
\hline
\end{tabular}

The results of the study are consistent with those of a previous study [30] that reported that about 42,607 hectares of land in the Indus delta are degraded due to surface seawater intrusion. Thus, tidal flood plains increased by $7.1 \%$ in 45 years. Rasul et al. [36] predicted a $5{ }^{\circ} \mathrm{C}$ rise in temperature over the Indus delta by the end of the 21st century. Other researchers reported that the main cause of the sediment deposition, subsurface seawater intrusion, and land degradation may be river flow to the delta [20]. The major causes of the expansion of tidal floods areas and barren land in the study area are synergic factors: decreased river flow, climate change, and seawater intrusion.

\subsection{Soil Salinity Indices}

Salt-affected and water-logged areas can be delineated with the help of various salinity indices [10]. Based on a histogram analysis of the derived salt-affected map, the spatial and temporal variability of soil salinity was characterized into five classes (Figure 6): nonsaline (green), low (light green), moderate (yellow), high (orange), and extreme (red). Following a previous study by Bannari [37], they divided SSSI-2 into six major classes. Furthermore, the visual analysis and validation of these classes by reference to field visits (ground truth) reveals good conformity in terms of the 2017 soil salinity NDSI and S1 results. The previous study reported that salinity indices such as NDSI and S1 had great potential for the detection of soil salinity compared to individual bands [38,39]. The extreme salinity class is characterized by the presence of high contents of soluble salt on the surface of the Jati and Shah Bandar areas. According to ground truth data, same talukas show higher values of EC and ESP (Figure 4a,d). A previous study reported that the vertical variability in the soil profile is the limiting factor in the assessment and mapping of soil salinity using remote sensing data because the spectral reflectance is unable to provide information on the whole soil profile; it only observes the soil surface [40,41]. The area under salinity stress increased significantly over 27 years (1990 to 2017). The main cause of seawater intrusion is the $80 \%$ decreased freshwater flow of the Indus River below Kotri barrage (the last barrage on the Indus River), and the reduction in sediment load after the late $1950_{\mathrm{S}}$ is considered the main cause of the increase in the size of the delta [42]. This study also corroborated the results of a previous study, which reported that the soil salinity increased by $10 \%$ in the last 45 years in the Indus delta [30]. 


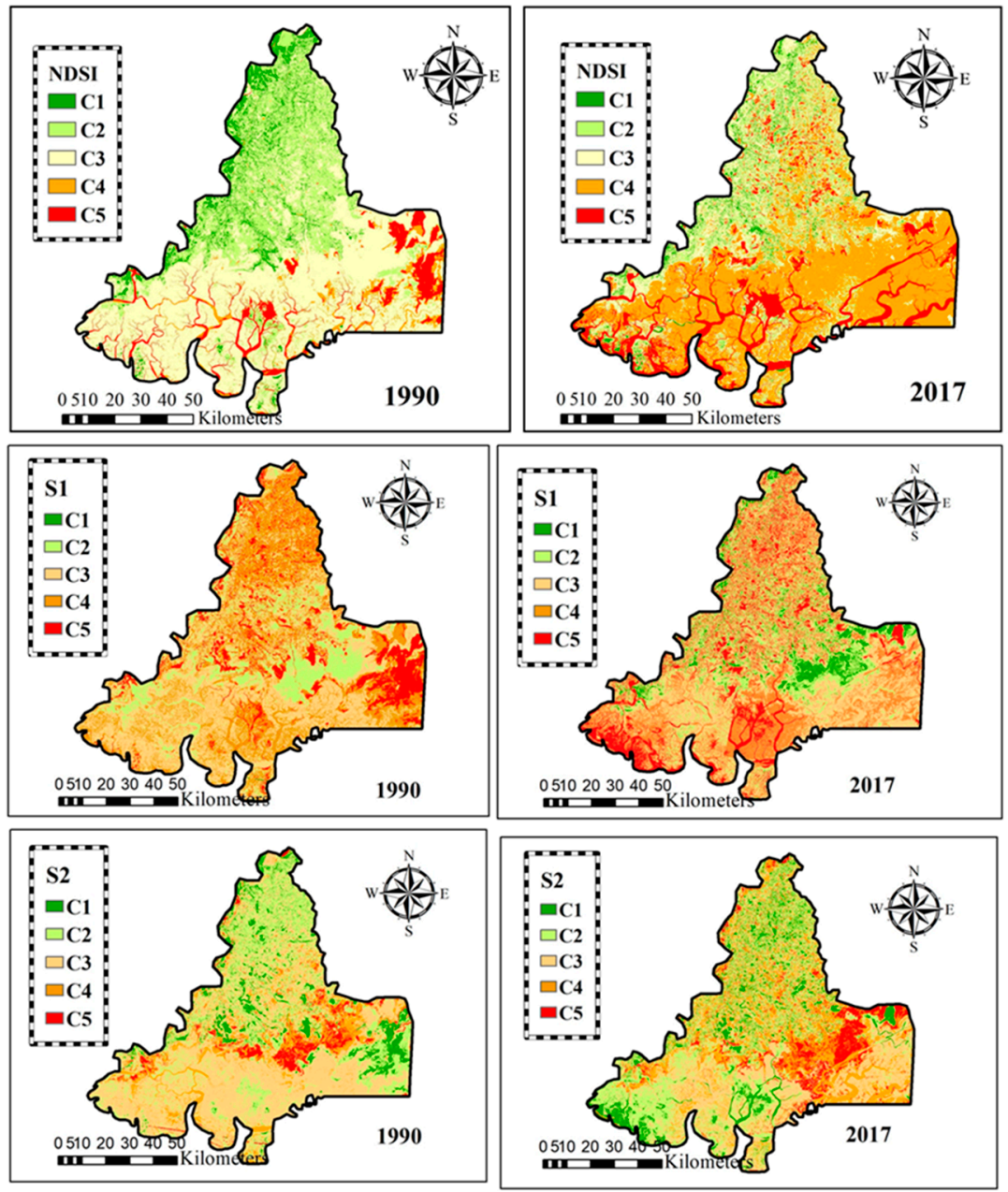

Figure 6. The temporal variation in soil salinity between 1990 and 2017, assessed using the normal different salinity index (NDSI), salinity index 1 (S1) and salinity index 2 (S2), highlighting five major salinity classes: non saline (green), low (light green), moderate (yellow), high (orange), and extreme (red).

\subsection{Correlation between Measured EC Data and Salinity Indices}

Soil salinity indices were applied to the satellite images and compared with the ground truth data. Several studies found a positive correlation between NDS1 and S1 and ground truth data [43,44]. Our results confirm that salinity index "S1" showed the highest correlation between results of EC 0-20 cm depth, which is consistent with the results of [45]. The study found a strong correlation between S1 and the measured EC, as shown in Table 5. Finally, spatial and temporal mapping of the soil salinity results indicated that two subdistricts of Sujawal, Jati and Shah Bandar, were highly affected. The results of field data (ground truth) show that almost $65.7 \%$ of samples' EC values exceeded the normal range. in the remote sensing data of NDSI and S1 in 2017 reveal that subdistricts Jati and Shah Bandar were more affected, as shown in Figure 6. This study agrees with Bouaziz et al. [44] and Fan et al. [46], who showed that vegetation indices such as SAVI, NDVI, and EVI had a low correlation with EC due to an insufficient density of vegetation cover, while soil EC indicates a higher correlation with salinity indices. 
Table 5. Correlation between EC and soil salinity indices.

\begin{tabular}{cccc}
\hline Parameters & NDSI & S1 & S2 \\
\hline EC & $0.879^{* *}$ & $0.934^{* *}$ & $0.874^{* *}$ \\
NDSI & - & $0.912^{* *}$ & 0.552 \\
S1 & - & - & $0.685^{*}$ \\
\hline
\end{tabular}

Note: Electrical conductivity (EC), normal differential salinity index (NDSI), salinity index 1 (S1), and salinity index 2 (S2). * **: significant at $p<0.05, p<0.01$, respectively.

\section{Conclusions}

This study investigated the soil salinity status from 1990 to 2017 in Sujawal district. Based on the field data (EC, pH, and ESP analysis), it was concluded that more than $50 \%$ of the soil's top layer was degraded by salinity in Sujawal district. Furthermore, satellite images were utilized to provide information about the changes in soil salinity. For the confirmation of field data, it was useful to note that the S1 index was highly correlated with the EC of field data. The classified satellite imagery from 1990 and 2017 showed that vegetation decreased by 8.6\%; in contrast, barren land and water bodies increased by $4.4 \%$ and $4.2 \%$, respectively. It was concluded that the use of remote sensing data is suitable for the discovery of soil salinity, with a lower cost compared to other conventional approaches. The current study is addressed to land managers, policy makers, and government officials who can use its findings to implement salinity control measures in the study area, i.e., the construction of protective bunds, increasing the mangrove population, and maximizing freshwater flow to the delta through the river as well as canals. Additionally, there should be efforts to minimize surface and subsurface seawater intrusion and combat the soil salinity problem in the district. Thus, this study can be extended in the future to test other multispectral/hyperspectral sensors' data in the same area and also other districts of Sindh that suffer from soil salinity.

Author Contributions: Data curation, K.A.S.; Funding acquisition, Y.W.; Methodology, A.A.S., and K.A.S. Software, K.A.S., B.A., A.A.S. and I.A.L.; Supervision, A.A.S. Validation, K.A.S., B.A.; Writing-original draft, K.A.S.; Writing-review and editing, K.A.S., Y.W., G.Z., F.S., I.A.L., G.Z., and B.A.

Funding: This work was supported by the Priority Academic Program Development (PAPD) of Jiangsu Higher Education Institutions.

Acknowledgments: This study was support by Priority Academic Program Development (PAPD) of Jiangsu Higher Education Institutions. We are thankful to Muhammad Munir Babar U.S.-Pakistan Center for Advanced Studies in Water Mehran University of Engineering \& Technology, Jamshoro 76062 Sindh, Pakistan, for his constructive comments and suggestions during field survey.

Conflicts of Interest: The authors declare no conflict of interest.

\section{References}

1. Akramkhanov, A.; Martius, C.; Park, S.J.; Hendrickx, J.M.H. Environmental factors of spatial distribution of soil salinity on flat irrigated terrain. Geoderma 2011, 163, 55-62. [CrossRef]

2. Kumar, N.; Singh, S.K.; Pandey, H.K. Drainage morphometric analysis using open access earth observation datasets in a drought-affected part of Bundelkhand, India. Appl. Geomat. 2018, 10, 173-189. [CrossRef]

3. Zaman, M.; Shahid, S.A.; Heng, L. Guideline for Salinity Assessment, Mitigation and Adaptation Using Nuclear and Related Techniques; Springer: New York, NY, USA, 2018; Volume 3, pp. 43-53.

4. Ennaji, W.; Barakat, A.; Karaoui, I.; El Baghdadi, M.; Arioua, A. Remote sensing approach to assess salt-affected soils in the north-east part of Tadla plain, Morocco. Geol. Ecol. Landsc. 2018, 2, 22-28. [CrossRef]

5. Louis, T.; Group, B. Sindh Irrigation and Drainage Authority Preparation of Regional Plan for Left Bank of Indus Project on Protective Plantation of Mangroves in the Coastal Areas of Left Bank. Sindh Water Sector Improvement Phase-1 Report-2012,1-22. Available online: http://sida.org.pk/download/lbg/phaseIII/ Volume\%20I\%20\&\%20II\%20-\%20Draft.pdf (accessed on 8 December 2019).

6. Azabdaftari, A.; Sunarb, F. Soil salinity mapping using multitemporal landsat data. Int. Arch. Photogramm. Remote Sens. Spat. Inf. Sci. 2016, 41, B7. 
7. Babiker, S.; Abulgasim, E.; Hamid, H.S. Enhancing the spatial variability of soil salinity indicators by remote sensing indices and geo-statistical approach. J. Earth Sci. Clim. Chang. 2018, 9, 1-7. [CrossRef]

8. Metternicht, G.I.; Zinck, J.A. Remote sensing of soil salinity: Potentials and constraints. Remote Sens. Environ. 2003, 85, 1-20. [CrossRef]

9. Allbed, A.; Kumar, L.; Aldakheel, Y.Y. Assessing soil salinity using soil salinity and vegetation indices derived from IKONOS high-spatial resolution imageries: Applications in a date palm dominated region. Geoderma 2014, 230, 1-8. [CrossRef]

10. Abbas, A.; Khan, S. Using remote sensing techniques for appraisal of irrigated soil salinity. MODSIM07-Land Water Environ. Manag. Integr. Syst. Sustain. Proc. 2007, 3, 2632-2638.

11. Balakrishnan, P.; Saleem, A.; Mallikarjun, N.D. Groundwater Quality Mapping Using Geographic Information System (GIS): A case study of Gulbarga City, Karnataka, India. Afr. J. Environ. Sci. Technol. 2011, 5, 1069-1084. [CrossRef]

12. Setianto, A.; Triandini, T. Comparison of Kriging and Inverse Distance Weighted (Idw) Interpolation Methods in Lineament Extraction and Analysis. J. Appl. Geol. 2015, 5, 21-29. [CrossRef]

13. Behera, S.K.; Shukla, A.K. Spatial distribution of surface soil acidity, electrical conductivity, soil organic carbon content and exchangeable potassium, calcium and magnesium in some cropped acid soils of India. L Degrad Dev. 2015, 26, 71-79. [CrossRef]

14. Mohammad, Z.-M.; Taghizadeh-mehrjardi, R.; Akbarzadeh, A. Evaluation of geostatistical techniques for mapping spatial distribution of soil $\mathrm{pH}$, salinity and plant cover affected by environmental factors in Southern Iran. Not. Sci. Biol. 2010, 2, 92-103.

15. Abbasnia, A.; Yousefi, N.; Mahvi, A.H.; Nabizadeh, R.; Radfard, M.; Yousefi, M.; Alimohammadi, M. Evaluation of groundwater quality using water quality index and its suitability for assessing water for drinking and irrigation purposes: Case study of Sistan and Baluchistan province (Iran). Hum. Ecol. Risk Assess. Int. J. 2019, 25, 988-1005. [CrossRef]

16. Farifteh, J.; Farshad, A.; George, R.J. Assessing salt-affected soils using remote sensing, solute modelling, and geophysics. Geoderma 2006, 130, 191-206. [CrossRef]

17. Asfaw, E.; Suryabhagavan, K.V.; Argaw, M. Soil salinity modeling and mapping using remote sensing and GIS: The case of Wonji sugar cane irrigation farm, Ethiopia. J. Saudi Soc. Agric. Sci. 2018, 17, 250-258. [CrossRef]

18. Solangi, G.S.; Siyal, A.A.; Babar, M.M.; Siyal, P. Groundwater quality evaluation using the water quality index (WQI), the synthetic pollution index (SPI), and geospatial tools: A case study of Sujawal district, Pakistan. Hum. Ecol. Risk Assess. 2019, 7039. [CrossRef]

19. Khan, M.A.; Alamgir, A.; Khan, A.; Shaukat, S.S.; Kazmi, S.J.; Qureshi, S.; Khanum, F. Appraisal of Climate Change Impacts on the Coastal Areas of Sindh Using Remote Sensing Techniques. Environ. Sci. 2015, 15, 1102-1112.

20. Majeed, S.; Zaman, S.B.; Ali, I.; Ahmed, S. Situational Analysis of Sindh Coast-Issues and Options. Manag. Nat. Resour. Sustain. Futur. Agric. Res. Brief. 2010, 2, 1-23.

21. Khuhawar, M.Y.; Brohi, R.O.Z.; Jahangir, T.M.; Lanjwani, M.F. Water quality assessment of Ramser site, Indus Delta, Sindh, Pakistan. Environ. Monit. Assess. 2018, 190, 492. [CrossRef]

22. Bouyoucos, G.J. Directions for making mechanical analyses of soils by the hydrometer method. Soil Sci. 1936, 42, 225-230. [CrossRef]

23. Heald, W.R. Methods of Soil and Plant Analysis With Special Reference to Strontium 90 Contamination; US Department of Agriculture: Washington, DC, USA, 1949.

24. Pessoa, L.G.M.; Freire, M.B.G.D.S.; Wilcox, B.P.; Green, C.H.M.; De Araújo, R.J.T.; De Araújo Filho, J.C. Spectral reflectance characteristics of soils in northeastern Brazil as influenced by salinity levels. Environ. Monit. Assess. 2016, 188, 616. [CrossRef] [PubMed]

25. Siyal, A.A.; Siyal, A.G.; Mahar, R.B. Spatial and temporal dynamics of Pai forest vegetation in Pakistan assessed by RS and GIS. J. Res. 2017, 28, 593-603. [CrossRef]

26. Enderle, D.I.M.; Weihjr, R.C. Integrating Supervised and Unsupervised Classification Methods to Develop a More Accurate Land Cover Classification. J. Ark. Acad. Sci. 2005, 59, 65-73.

27. Khan, N.M.; Rastoskuev, V.V.; Sato, Y.; Shiozawa, S. Assessment of hydrosaline land degradation by using a simple approach of remote sensing indicators. Agric. Water Manag. 2005, 77, 96-109. [CrossRef] 
28. Qingsheng, L.; Gaohuan, L.; Jun, Z. The indication function of soil type and soil texture and land type to soil salinization levels. Chin. Agric. Sci. Bull. 2008, 24, 297-300.

29. González, F.J.; Basson, T.; Schultz, B. Final report of IPOE for review of studies on water escapages below Kotri Barrage. Unpubl. Rep. Int. Panel Expert Pak. 2005, 5, 1-43.

30. Solangi, G.S.; Siyal, A.A.; Babar, M.M.; Siyal, P. Spatial Analysis of Soil Salinity in the Indus River Delta, Pakistan. Eng. Technol. Appl. Sci. Res. 2019, 9, 4271-4275.

31. Faouzi, M.; Larabi, A. Problématique de la remontée, de la salinité et de la pollution par les nitrates des eaux de la nappe phréatique des Beni-Amir (Tadla, Maroc). Ingénieries-EAT 2001, 27, 23-36.

32. Altaf, P.; Siyal, A.; Centers, U.S.; Studies, A. Climate Change: Assessing Impact of Seawater Intrusion on Soil, Water and Environment on Indus Delta Using GIS and Remote Sensing Tools Final Report 2018 Principal Investigator. 2018. Available online: https://www.researchgate.net/project/Climate-ChangeAssessing-impact-of-seawater-intrusion-on-Soil-Water-and-Environment-on-Indus-delta-using-GISRemote-Sensing-tools (accessed on 8 December 2019).

33. Yu, J.; Li, Y.; Han, G.; Guan, B. The Spatial Distribution Characteristics of Soil Salinity in Coastal Zone of the Yellow River Delta. Environ. Earth Sci. 2014, 72, 589-599. [CrossRef]

34. Allbed, A.; Kumar, L. Soil Salinity Mapping and Monitoring in Arid and Semi-Arid Regions Using Remote Sensing Technology: A Review. Adv. Remote Sens. 2013, 2, 373-385. [CrossRef]

35. Lea, C.; Curtis, A.C. Thematic Accur acy Assessment Procedures. Nat. Resour Rep. 2010, 1-90.

36. Mahmood, A.; Sadiq, A.; Khan, S.I. Vulnerability of the Indus Delta to Climate Change in Pakistan. Pak. J. Meteorol. 2012, 8, 89-107.

37. Bannari, A.; El-Battay, A.; Hameid, N.; Tashtoush, F. Salt-Affected Soil Mapping in an Arid Environment Using Semi-Empirical Model and Landsat-OLI Data. Adv. Remote Sens. 2017, 6, 260-291. [CrossRef]

38. Allbed, A.; Kumar, L.; Sinha, P. Mapping and modelling spatial variation in soil salinity in the Al Hassa Oasis based on remote sensing indicators and regression techniques. Remote Sens. 2014, 6, 1137-1157. [CrossRef]

39. Tripathi, N.K.; Rai, B.K.; Dwivedi, P. Spatial modeling of soil alkalinity in GIS environment using IRS data. In Proceedings of the 18th Asian Conference on Remote Sensing, Kuala Lumpur, Malaysia, 20-24 October 1997.

40. Singh, G.; Bundela, D.S.; Sethi, M.; Lal, K.; Kamra, S.K. Remote sensing and geographic information system for appraisal of salt-affected soils in India. J. Environ. Qual. 2010, 39, 5-15. [CrossRef]

41. Siyal, A.A.; Lakhair, I.; Babar, M.M.; Siyal, P.; Solangi, G.S. Study of Soil, Water, and Cropping Pattern in Danastar Wah (Manchar Lake) Command Area Using Geospatial Tools. Mehran Univ. Res. J. Eng. Technol. 2018, 37, 655-668. [CrossRef]

42. Mahar, G.A.; Zaigham, N.A. Examining Spatio-Temporal Change Detection in the Indus River Delta with the Help of Satellite Data. Arab. J. Sci. Eng. 2015, 40, 1933-1946. [CrossRef]

43. Noroozi, A.A.; Homaee, M.; Farshad, A. Integrated application of remote sensing and spatial statistical models to the identification of soil salinity: A case study from Garmsar Plain, Iran. Environ. Sci. 2012, 9, 59-74.

44. Bouaziz, M.; Matschullat, J.; Gloaguen, R. Improved remote sensing detection of soil salinity from a semi-arid climate in Northeast Brazil. Comptes. Rendus. Geosci. 2011, 343, 795-803. [CrossRef]

45. Douaoui, A.E.K.; Nicolas, H.; Walter, C. Detecting salinity hazards within a semiarid context by means of combining soil and remote-sensing data. Geoderma 2006, 134, 217-230. [CrossRef]

46. Fan, X.; Pedroli, B.; Liu, G.; Liu, Q.; Liu, H.; Shu, L. Soil salinity development in the yellow river delta in relation to groundwater dynamics. L Degrad Dev. 2012, 23, 175-189. [CrossRef]

(C) 2019 by the authors. Licensee MDPI, Basel, Switzerland. This article is an open access article distributed under the terms and conditions of the Creative Commons Attribution (CC BY) license (http://creativecommons.org/licenses/by/4.0/). 